\title{
Connectivity Shapes Functional Diversity and Maintains Complementarity in Surf Zones on Exposed Coasts
}

\author{
Christopher J. Henderson ${ }^{1}$ (D) - Ben L. Gilby ${ }^{1} \cdot$ Andrew D. Olds $^{1}$. Jesse Mosman ${ }^{1} \cdot$ Rod M. Connolly $^{2} \cdot$ Glenn Hyndes $^{3}$. \\ Brendan Kelaher ${ }^{4}$ Brooke Maslo ${ }^{5}$. Alan Williams ${ }^{6}$. Thomas A. Schlacher ${ }^{1}$
}

Received: 30 August 2021 / Revised: 4 January 2022 / Accepted: 6 January 2022 / Published online: 21 January 2022

(c) The Author(s) 2022

\begin{abstract}
Habitat complexity and connectivity can influence the number of species and their diversity across a landscape. For the surf zones of ocean-exposed beaches, globally one of the longest habitat interfaces, the assumed low structural complexity, and apparent homogeneity, of the sandy seafloor habitats predicts low taxonomic and functional diversity. Here, we assessed how the configuration of the seascape and the context of different beach structure functional diversity and functional niche space of fish assemblages in surf zones. We expected that beaches that were well connected with highly productive and complex estuarine and reef habitats would support a greater level of functional diversity, and a greater degree of functional complementarity within different niches. We sampled surf zones at twenty-five beaches along $50 \mathrm{~km}$ of coastline in southeast Queensland, Australia. We calculated functional diversity and functional niche space using variation in the functional traits of fish assemblages. We found that increased proximity with nearby subtidal rocky reefs was the key feature of the coastline shaping functional diversity and functional niche space in surf zone fishes. These effects resulted in increased functional complementarity within a number of fish functional group niches when rocky reefs were nearby. We provide empirical evidence that habitat proximity can structure functional diversity and complementarity in the surf zones of ocean beaches, a system traditionally viewed as having low habitat heterogeneity. Our results highlight the focus management must take in conserving these highly connected ecosystems to avoid negative functional consequences.
\end{abstract}

Keywords Ecosystem function · Connectivity · Complexity · Fish · Reef · Trophic niche

\section{Introduction}

Communicated by Masahiro Nakaoka.

Christopher J. Henderson

chender1@usc.edu.au

1 School of Science, Technology and Engineering, University of the Sunshine Coast, Maroochydore, QLD 4558, Australia

2 Australian Rivers Institute - Coasts and Estuaries, and School of Environment and Science, Griffith University, Gold Coast, QLD 4222, Australia

3 Centre for Marine Ecosystems Research, School of Science, Edith Cowan University, Perth, WA, Australia

4 National Marine Science Centre, Southern Cross University, Coffs Harbour, NSW, Australia

5 Department of Ecology, Evolution and Natural Resources, The State University of New Jersey, RutgersNew Brunswick, NJ, USA

6 CSIRO Oceans \& Atmosphere, PO Box 1538, Hobart, TAS, Australia
Animals perform a diversity of ecological functions that are critical in setting the structure and functioning of ecosystems (Cardinale et al. 2006; Loreau and de Mazancourt 2013), and it is the traits (i.e., physiological, morphological or behavioural) of those different animals that alters their ability to provide different ecological functions within an ecosystem (Bellwood et al. 2019). The distribution of ecological functions, in terms of type and intensity, is typically heterogeneous due to spatial differences in species composition, abiotic factors, connectivity, habitat quality and complexity, and human disturbance (Graham and Nash 2012; Mayer-Pinto et al. 2018; Mouillot et al. 2013; Rolo et al. 2018). Given the large number of factors that potentially drive variation in ecological functions and the species that provide them, identifying key determinants and their interactions is of fundamental importance (Cadotte et al. 2011; Mouillot et al. 2013). 
The composition of animal assemblages is often instrumental in shaping ecological functions. As is the case for functional or trait diversity across land or seascapes more widely, assemblage composition is influenced by a host of factors including, but not limited to, food quality and availability, interspecific interactions, habitat types and distributions, and the physiological tolerances of species (Henderson et al. 2019; Nash et al. 2016). It is generally accepted that increased proximity to a greater number of habitats provides better feeding opportunities for more species and individuals, hypothetically creating more niches, that more species can occupy (Lohbeck et al. 2016; Micheli and Halpern 2005; Rosenfeld 2002). Thus, niche space may vary spatially depending on the proximity between habitats and ecosystems within a seascape (Clavel et al. 2011; Fetzer et al. 2015; Henderson et al. 2020; Mouillot et al. 2013). The niche space that is occupied by different species groups can identify the levels of complementarity within that specific group, with those groups with a larger niche space representing greater levels of complementarity and potentially greater resilience to change (Blüthgen and Klein 2011; Paquette and Messier 2011).

Coastal seascapes are composed of a mix of ecosystems and habitat types of varying physico-chemical conditions, topography, complexity, and productivity, which determine the types, abundance, and distribution of species of functional importance (Hyndes et al. 2014; Olds et al. 2018a). Sandy beaches dominate coastlines across the globe, with surf zones (the areas of breaking waves seaward of the shore) being an integral part of ocean beaches. Key attributes of surf zones along exposed ocean beaches are strong wave energy and currents, and highly variable primary productivity (e.g., estuarine matter delivered in plumes, dislodged algae and seagrass washed ashore, patches of intense phytoplankton growth) (Schlacher et al. 2015). Surf zones are also characterised to varying degrees by structurally complex shifting sand banks and troughs, hydrodynamic complexity, seafloor relief, effects from nearby urbanisation (e.g. altered beach conditions and the construction of barriers, VargasFonseca et al. 2016), and a gradient of seascape contexts (e.g., area of nearby habitat or anthropogenic disturbance) (Mosman et al. 2020). These factors can alter the abundance and diversity of fish assemblages (Olds et al. 2018b). However, linkages between surf zones and nearby structurally complex (e.g., rocky reefs and headlands) and/or highly productive ecosystems (e.g., estuaries) suggest that the diversity and abundance of fish in surf zones can be higher than anticipated under certain seascape configurations (Ayvazian and Hyndes 1995; Ortodossi et al. 2019; Vargas-Fonseca et al. 2016). The ways in which different seascape configurations alter functional diversity within surf zones assemblages has, however, never been quantified (Olds et al. 2018b).
Surf zones represent a suitable system to test for the effects of seascape configuration, connectivity, and complexity on fish functional diversity because they represent a critical link in the coastal mosaic and because surf zone fish assemblages are sensitive to numerous effects, including connectivity, exposure, and urbanisation (Borland et al. 2017; Ortodossi et al. 2019; Vargas-Fonseca et al. 2016). These fish communities also perform numerous ecological functions in this ecosystem, including predation at a variety of trophic levels, the consumption of carrion, and in some settings, herbivory, and the spatial distribution of the species that perform these functions are linked to changes in beach and surf zone context (Hyndes et al. 2014; Ortodossi et al. 2019; Vargas-Fonseca et al. 2016). Our aims here were to (1) determine how changes in spatial proximity to alternative habitats (e.g., distance to the nearest estuaries, headlands, or subtidal reefs) influence the functional diversity of fish assemblages in surf zones of ocean beaches and (2) measure changes to the dimensions of functional niche space in relation to the presence of, and proximity to other habitat types in the broader seascape of which surf zones are embedded.

\section{Methods}

\section{Study Beaches}

We sampled fish assemblages at 25 ocean beaches spanning ca. $50 \mathrm{~km}$ of exposed coastline in SE Queensland, Australia (Fig. 1a). The beaches encompass a range of environmental conditions with respect to (1) their proximity to the nearest rocky reefs, (2) their proximity to prominent rocky headlands, (3) their proximity to estuarine inlets, (4) the extent of urbanisation landwards, and (5) their aspect (orientation) in relation to predominant winds and waves. All beaches sampled are of the intermediate morphodynamic type (Maslo et al. 2016). We used Quantum GIS (Quantum 2013) to measure the proximity of all beach sites to the nearest headland, rocky reef and estuary, beach width, and surf zone width, and to calculate the area of urbanisation within a $4-\mathrm{km}^{2}$ buffer of each beach (Vargas-Fonseca et al. 2016). We, unfortunately, did not have information on the varying levels of rocky reef complexity across our sampling range and therefore are not able to infer about the effects of complexity outside of any effects of habitat proximity.

\section{Field Sampling}

We sampled fish assemblages during the austral winter, using baited remote underwater video systems (BRUVS). We deployed sets of cameras in two parts of the surf zone: in nearshore troughs (typically $20-50 \mathrm{~m}$ seawards from the swashline) and over offshore bars (150-250 m offshore) 


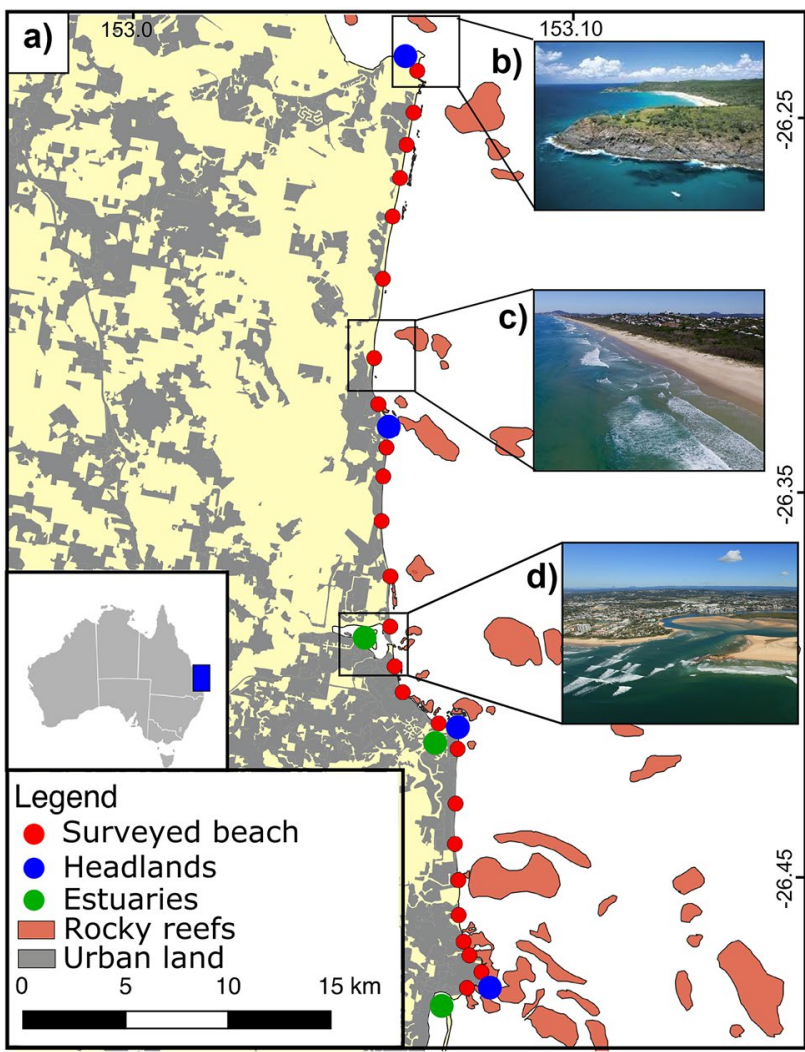

Fig. 1 a Location of 25 surf zones of ocean-exposed sandy beaches in south-east Queensland, Australia. Sandy beaches vary primarily with respect to their seascape context, with some beaches located $\mathbf{b}$ near headlands, $\mathbf{c}$ on long stretches of coastline, $\mathbf{d}$ close to the mouth of estuaries, and the extent of urban development landwards. Here, nearshore reefs are rocky reefs with some algae and low coral cover

where waves first break (Borland et al. 2017). The longshore distance between cameras was set at $200 \mathrm{~m}$ to lower the probability that multiple cameras detecting the same individuals multiple times (Wraith et al. 2013). BRUVS were dropped at consistent depths within the two parts of each beach; however, we were unable to ensure consistency between beaches as site selection at each beach was dependent on wave position. The BRUVS consisted of a GoPro camera recording in HD, mounted to a $15-\mathrm{kg}$ weight and a float. The bait was $500 \mathrm{~g}$ of pilchards (Sardinops sagax) placed in a coarse ( $5 \mathrm{~mm}$ aperture) mesh bag mounted on a PVC pole $1 \mathrm{~m}$ in front of the cameras. We used a baited approach over a non-baited approach as it is found to sample a broader portion of the fish community (Harvey et al. 2007; Watson et al. 2005). Each camera recorded for $1 \mathrm{~h}$ during the daytime, yielding a total sampling effort of $250 \mathrm{~h}$ of video footage ( 25 sites $\times 10$ cameras per site $\times 1 \mathrm{~h}$ recording). All sampling occurred $2 \mathrm{~h}$ either side of high tide to ensure that nearshore troughs were filled with water. As temporal variation was not a focus of this study, we only sampled fish communities during daytime hours in winter to maximise water clarity and minimise wave conditions. To lower the influences of short-term variations in wave regimes, we only deployed cameras at high tide, on days (a 4-h period) when wave periods were $<10 \mathrm{~s}$ and wave height was $<1.5 \mathrm{~m}$. The principal data extracted from the videos were the standard MaxN statistic for each species identified (Ellis 1995; Willis and Babcock 2000). The MaxN statistic refers to the maximum number of individuals of the same species in a single frame throughout an entire video. This is used to ensure the same individual fish is not counted multiple times.

\section{Functional Diversity Metrics}

Functional diversity (Bellwood et al. 2019; Laliberté and Legendre 2010; Mason et al. 2005; Mouchet et al. 2010) is indexed as variation in traits of fish species, with these traits being extracted from FishBase, using the rfishbase package in R (see Table S1, Froese and Pauly 2018). To broadly sketch functional niche space of surf-zone fish, we used traits that code for trophic biology (i.e., feeding mode, trophic level, trophic guild) and traits that describe general morphology (i.e., maximum total length, body shape, body depth, head length, pre-orbital length, eye diameter) (Brandl and Bellwood 2014; Elliott et al. 2007; Wainwright and Richard 1995). In order to account for categorical traits, our dendrogram was based on a Gower dissimilarity matrix with clustering based on average trait values (Petchey and Gaston 2006). We then partitioned the assemblage into seven different groups based on their functional feeding group (e.g., zoobenthivore, zooplanktivore, piscivore, omnivore, corallivore, herbivore, and detritivore).

Functional diversity was numerically expressed using three functional metrics and one taxonomic metric, with (i) functional richness, (ii) functional dispersion, (iii) functional evenness, and (iv) species richness, calculated with the fundiv and $F D$ packages in $\mathrm{R}$ (Gagic et al. 2015; Laliberté and Legendre 2010; Mason et al. 2005). Functional richness (sensu Petchey and Gaston 2006) quantifies the area of functional trait space in an ecosystem (Mason et al. 2005). Functional dispersion describes the mean distance in functional trait space for each species from the centroid of all species in an assemblage; it is weighted by abundance (i.e., MaxN) (Laliberté and Legendre 2010). Functional evenness is quantified as the distribution of the abundance of individuals within different niches within a community (Mason et al. 2005).

\section{Data Analyses}

To assess how variation in environmental variables (Table 1) influences spatial variation in the functional diversity of assemblages between beaches, we used generalised additive models (GAMs) in R using the $m g c v$ and MuMIn 
Table 1 Environmental variables tested in this study for their influence on functional diversity of fishes in surf zones of ocean-exposed sandy beaches

\begin{tabular}{|c|c|c|}
\hline Variable & Definition & Rationale / Predictive Hypothesis \\
\hline Distance to reef & $\begin{array}{l}\text { The separation of a beach from the edge of the nearest } \\
\text { subtidal reef seawards of that beach }\end{array}$ & $\begin{array}{l}\text { Nearby subtidal rocky reefs add habitat heterogeneity and/ } \\
\text { or structural complexity to the broader seascape that surf } \\
\text { zones form part of; this increased complexity is predicted } \\
\text { to translate into greater species richness and functional } \\
\text { diversity of fishes (Ortodossi et al. 2019) }\end{array}$ \\
\hline Distance to headland & $\begin{array}{l}\text { The longshore gap between a beach and the nearest } \\
\text { headland }\end{array}$ & $\begin{array}{l}\text { Habitat complexity added by nearby headlands to mainly } \\
\text { sedimentary coast is expected to increase biodiversity, } \\
\text { abundance and functional diversity of fishes (Ortodossi } \\
\text { et al. 2019). Therefore, we predicted that surf zones near } \\
\text { rocky headlands support more fish species of greater } \\
\text { functional heterogeneity }\end{array}$ \\
\hline Distance to estuary & $\begin{array}{l}\text { The longshore gap between a beach and the nearest } \\
\text { estuarine inlet }\end{array}$ & $\begin{array}{l}\text { Estuaries frequently export, largely in the form of plumes, } \\
\text { nutrients, and organic matter to nearshore marine waters, } \\
\text { including the surf zones of ocean beaches. These fluxes } \\
\text { can provide trophic subsidies and are therefore predicted } \\
\text { to enhance the abundance, and possibly also the diversity, } \\
\text { of fishes in the surf zone (Hyndes et al. 2014; Valesini } \\
\text { et al. 2004) }\end{array}$ \\
\hline Urbanisation & $\begin{array}{l}\text { The area of urban land within a } 4 \mathrm{~km}^{2} \text { buffer immediately } \\
\text { landwards of the beach. This dimension was chosen to } \\
\text { index the immediate impact of urbanisation on surf-beach } \\
\text { systems }\end{array}$ & $\begin{array}{l}\text { Conversion of dunes backing beaches to urban areas } \\
\text { fundamentally changes the human footprint of beach } \\
\text { ecosystems, notably increasing visitation, nourishment, } \\
\text { armouring, grooming, and watercraft use in the surf } \\
\text { zone. These multiple forms of human activities have been } \\
\text { shown to influence fish assemblages in the surf zone of } \\
\text { sandy beaches, suggesting mostly detrimental impacts on } \\
\text { fishes (Vargas-Fonseca et al. 2016) }\end{array}$ \\
\hline Beach Width & $\begin{array}{l}\text { The distance from the strand line to the edge of the water } \\
\text { at low tide }\end{array}$ & $\begin{array}{l}\text { Beach width is a key variable defining the morphodynamic } \\
\text { state of ocean beaches, with narrow reflective beaches } \\
\text { typically having a narrow surf zone with smaller waves, } \\
\text { whereas wide dissipative beaches are being fronted by } \\
\text { expansive surf zones with larger waves. Since wave energy } \\
\text { in wide surf zones is dissipated often on the outer bars, } \\
\text { lower-energy conditions can prevail in nearshore throughs, } \\
\text { suggesting a positive influence on fish abundance and/or } \\
\text { diversity (Marin Jarrin and Miller 2016) }\end{array}$ \\
\hline Beach Aspect & $\begin{array}{l}\text { Northness and eastness of each beach. A measure of swell } \\
\text { direction (Hill et al. 2014) }\end{array}$ & $\begin{array}{l}\text { Beaches that face the dominant swell direction are likely } \\
\text { to experience a higher-energy wave climate, which we } \\
\text { predict may lower fish abundance and diversity (Borland } \\
\text { et al. 2017) }\end{array}$ \\
\hline
\end{tabular}

packages (Barton 2013; Wood and Wood 2015). GAMs were chosen instead of other regression models because we could not assume linear relationships. We fit models with all possible combinations of three or fewer environmental variables and restricted individual models to four polynomial functions or fewer to minimise model overfitting. Models were compared using Akaike information criterion (AICc) corrected for small sample sizes and assessed models for auto-correlation using the $a c f$ function in R. Best fit models are calculated using the 'dredge' function, and were considered to be those with the lowest AICc value and within 2 AICc values of the best fit model. The relative importance of variables in each model was calculated by summing weighted AICc values across all models containing the variable of interest (Bartoń 2013; Henderson et al.
2020). We identified the most 'important' factor across all models, based on summed importance values across best-fit GAM models for each different metric.

The proximity of sampling sites in the surf zones of beaches to subtidal rocky reefs was categorised into four distance classes, based on visual examination of the distribution: (i) 'at reef' (i.e., there was subtidal rocky reef present within the extent of the beach that was sampled), (ii) 'close' (mean $494 \mathrm{~m}$, range 161-659 m), (iii) 'intermediate' (mean: $1061 \mathrm{~m}$, range 922-1291 m), and 'far' (mean $2572 \mathrm{~m}$, range 2464-2752 m) (see Fig. S2). We used these distance categories to visualise how functional niche space (sensu Layman et al. 2007) varies in relation to seascape context. The underlying resemblance matrix was based on Gower dissimilarity (to allow for inclusion 
of categorical variables) of the original functional traits extracted. Functional niche space was then displayed using a principal coordinate analysis spider plots, based on the Gower dissimilarity matrix of the original functional traits. Functional niche space was shown for each functional group at each of the four distances from reef. Spider plots are a suitable representation of trait space as they highlight the outer bounds of the niche space, and the diversity of species in particular areas of the niche relative to the mean traits for that functional grouping. This makes for a suitable plot when highlighting complementarity in functional niches.

\section{Results}

\section{Landscape Connectivity Shapes Functional Diversity of Fish in Surf Zones}

Seventy species, in seven functional groups, were recorded in the surf-zone of the study region's beaches.
The functional group with the most species (37 spp.) was zoobenthivores, followed by piscivores (17 spp.) and omnivores (8 spp.) (see Fig. S1; Table S1). Other groups in our analysis included zooplanktivores (5 spp.), detritivores ( $3 \mathrm{spp}$.), herbivores ( $2 \mathrm{spp}$.), and corallivores (1 sp.). Species richness per site varies between 6 and 28 , and this spatial pattern is measurably influenced by the configuration of beaches within the broader coastal seascape. More species occur in surf zones that contain or were near to reefs (i.e., within $600 \mathrm{~m}$ ) and that are no further than $5000 \mathrm{~m}$ from estuarine inlets; surf zones more distant from rocky headlands also contained more species (Fig. 2; Table 2).

Overall, distance to rocky reefs was the most important factor being included in the best fit models for all metrics measured (Fig. 3; Table 2). Functional diversity of fishes is highest in surf zones that had reefs or are close $(<600 \mathrm{~m})$ to reefs (Fig. 2; Table 2). Spatial patterns of functional richness resemble those for the number of species, being highest near reefs and more distant
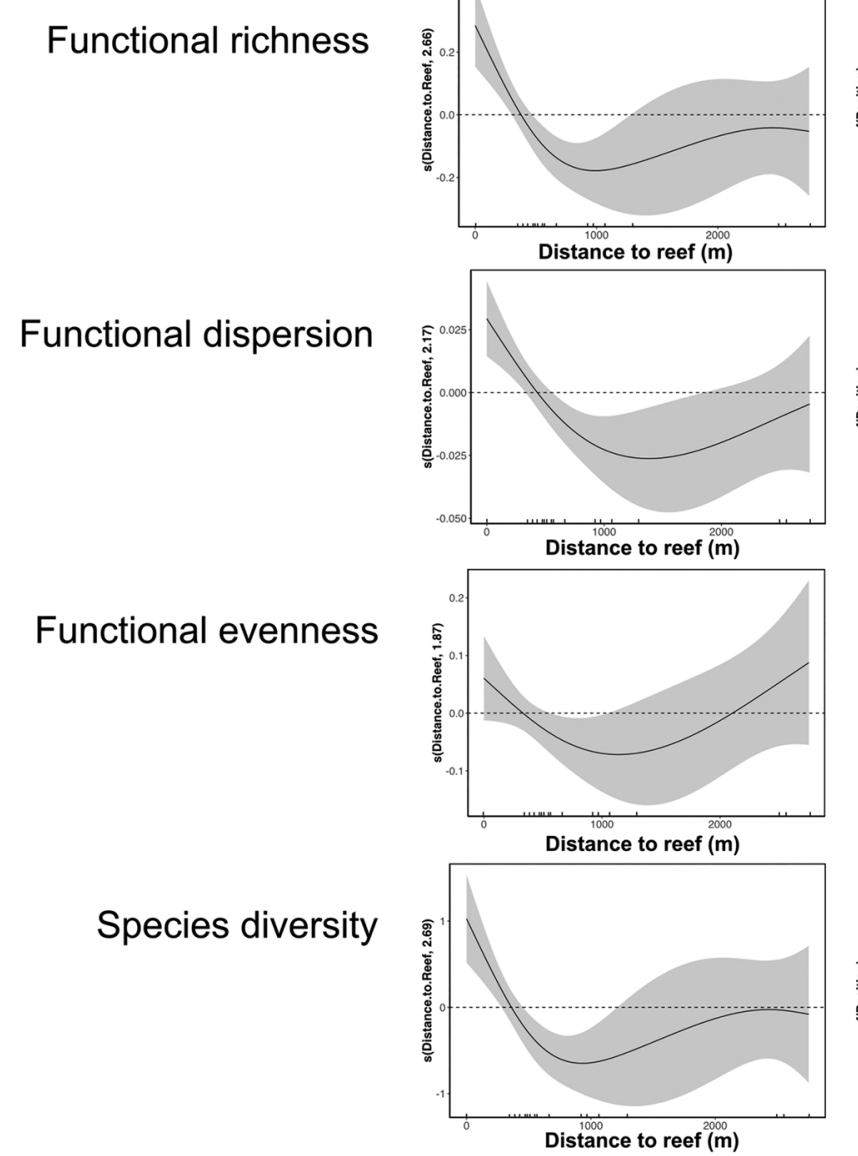

Fig. 2 Generalised additive model (GAM) partial plots illustrating significant relationships between the seascape configuration of surf zones in the broader habitat mosaic (indexed by distance to the near-
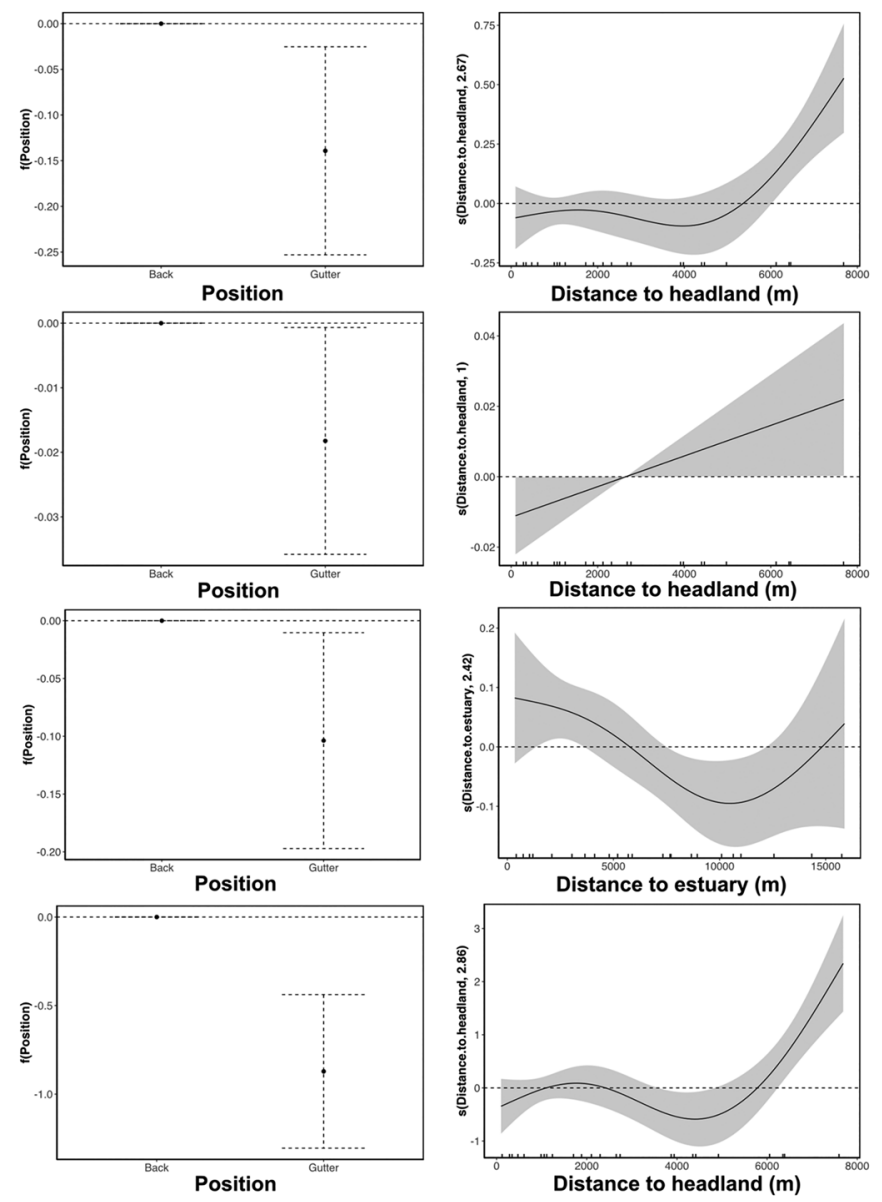

est offshore reef, estuarine, or headland; see Fig. 1). and measures of fish functional diversity and species richness 
Table 2 Best fit generalised additive models (GAMs) between species richness and functional diversity metrics and the suite of environmental predictors (cf. Table 1 for full list of environmental variables and functional responses predicted; variables in bold denote signifi- cant $(p<0.05)$ predictors in the best fit model. Importance values are in superscript, denoting the relative contribution of each variable to the overall model fit). Number of other models with 2 AICc values is highlighted for each best-fit model

\begin{tabular}{|c|c|c|c|c|c|}
\hline Community metrics & Best fit model & $\mathrm{R}^{2}$ & df & $\mathrm{AICc}$ & $\begin{array}{l}\text { \# other } \\
\text { models }\end{array}$ \\
\hline Functional richness & Distance to reef ${ }^{(1.0, p<0.001)}+$ Distance to headland $^{(0.99, p=0.004)}+$ Placement $^{(0.72, p=0.018)}$ & 0.24 & 8 & 296.5 & 0 \\
\hline Functional dispersion & Distance to reef ${ }^{(0.96, p=0.001)}+$ Distance to headland ${ }^{(0.57, p=0.048)}+$ Placement $^{(0.65, p=0.043)}$ & 0.09 & 5 & -582.9 & 2 \\
\hline Functional evenness & Distance to reef ${ }^{(0.50, \boldsymbol{p}=0.08)}+$ Distance to estuary ${ }^{(0.79,, \boldsymbol{p}=0.08)}+$ Placement $^{(\mathbf{0 . 7 0}, \boldsymbol{p}=\mathbf{0 . 0 3 1})}$ & 0.09 & 7 & 193.8 & 4 \\
\hline Species richness & Distance to reef ${ }^{(0.99, p<0.001)}+$ Distance to headland ${ }^{(0.99, p<0.001)}+$ Placement $^{(1.0, p<0.001)}$ & 0.27 & 8 & 900.4 & 0 \\
\hline
\end{tabular}

from headlands (Fig. 2; Table 2); similarly, functional dispersion was highest when reefs are in or close to surf zones (Fig. 2; Table 2). Sampling position within the surf zone was also a significant factor in structuring functional diversity and species richness, with all measures of functional and species diversity being higher on offshore bars compared to nearshore gutters (Fig. 2; Table 2). We did not find an effect of beach width, surf zone width, urbanisation, or beach aspect on any functional diversity metrics.

\section{Proximity to Reefs Determines Functional Niche Space}

Functional niche space of fish functional groups was greatest for most groups in surf zones with nearby rocky reefs (Fig. 4). By contrast, fish functional groups in all surf zones without nearby reefs had similar niche spaces, with this being lowest at beaches furthest away from reefs (Fig. 4). All fish functional groups reduced in species diversity, which generally let to a decrease in functional
Fig. 3 Standardised importance values for factors included in the best-fit generalised additive models relating functional diversity and richness of fishes in surf zones to environmental predictors (Table 2)

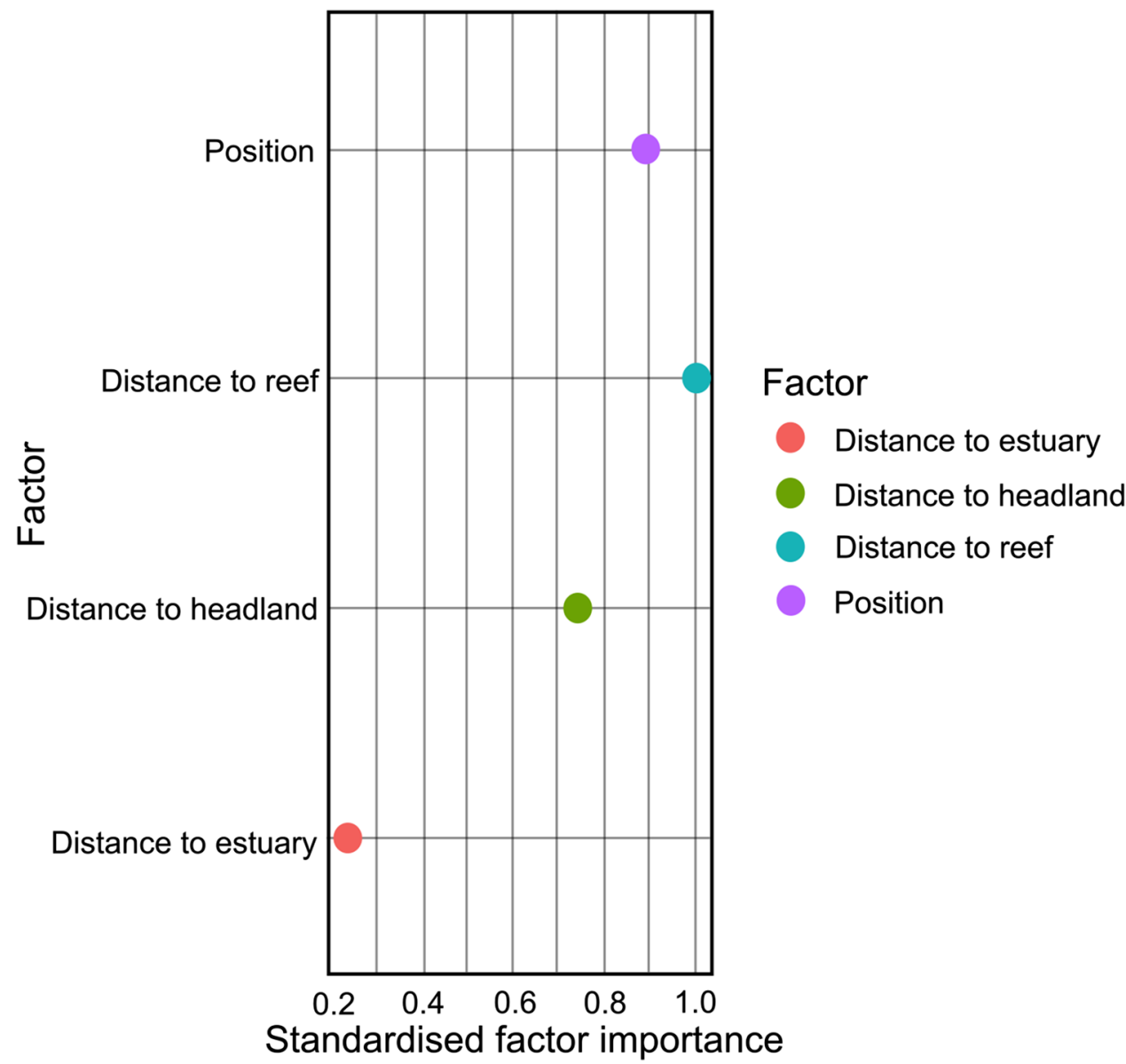



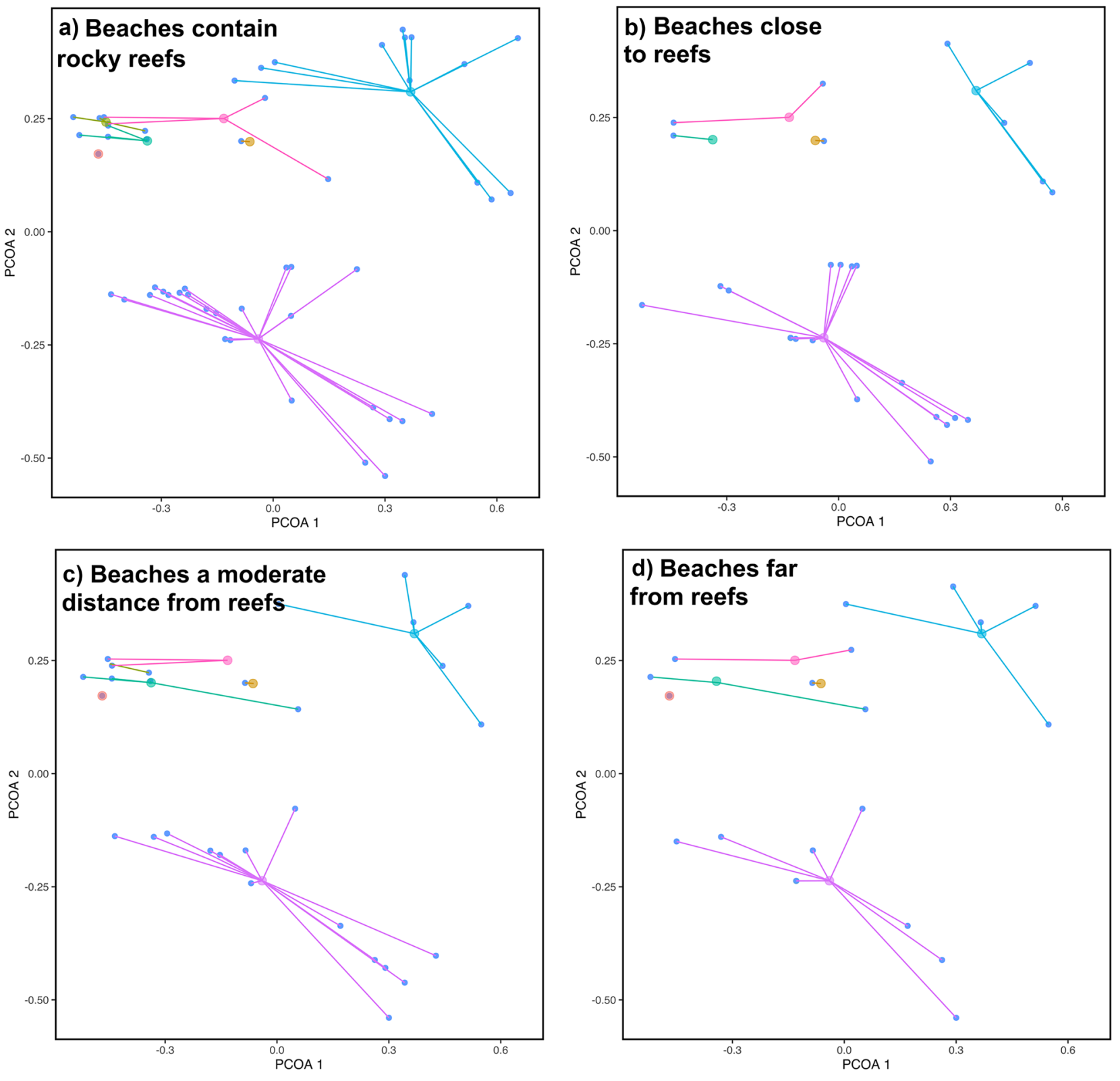

Legend

Corallivore

Detritivore

Herbivore

Omnivore

Piscivore

Zoobenthivore

Zooplanktivore

Fig. 4 Changes in functional niche space for functional groups of fish in the surf zone of beaches that are located at different distances from rocky reefs. Plots are ordinations (principal coordinates analysis) of trait dispersion based on resemblance between species over their full trait spectrum analysed. Centroids for each group represent the aver-

niche space. For the two most diverse groups, zoobenthivores and piscivores, they experienced a significant reduction in diversity; however, due to the variability of traits in these groups, niche space only reduced slightly (Fig. 4). age trait values for all species within a functional grouping. Functional niche size was highest at a beaches containing reef (i.e., there was subtidal rocky reef present within the extent of the beach that was surveyed) and decreased at sites $\mathbf{b}$ close to reef, $\mathbf{c}$ at intermediate distances, and $\mathbf{d}$ at beaches furthest away from reefs 
largely untested whether and how these variables interact to modify functional diversity (Cadotte et al. 2011; Cheal et al. 2013; Nock et al. 2013; Rolo et al. 2018). Here, we show that beach systems with surf zones that contained reefs, or were close to reefs, supported fish assemblages that contained more species, and a greater diversity of functional groups. The same beaches also had fish assemblages composed of functional groups that had a broader niche space and increased complementarity in most of the fish functional groups when reefs were present in the surf zone. We found lower functional complementarity at beaches further from reefs in the functional groups containing piscivore, zooplanktivores, and zoobenthivore, with reduced functional niche space, and thus reduced complementarity. Our findings for surf zone fish concur with studies describing generally positive effects of habitat proximity with nearby structurally complex ecosystems on faunal assemblages in a variety of different ecosystems on land, and in the sea (Fischer and Lindenmayer 2007). We did, however, not find strong effects of proximity with headlands, estuaries or urbanisation on functional diversity in surf zones. We expect that the diminished impacts of headlands may be due to the heightened importance of nearshore reefs, with not all headlands on this coastline having extensive reefs. Similarly, estuaries along this coastline do not contain extensive urbanisation, and therefore, there are no in-water structure at the mouth (e.g., there are no offshore pointing jetties in this region), and sampling occurred during the season when rainfall is lowest (Marin Jarrin and Miller 2016). Our findings suggest that the filtering effects of proximity with structurally complex habitats such as subtidal reefs can have significant impacts for not only biodiversity, but also the functional composition of assemblages (Baguette et al. 2013; Rudnick et al. 2012; Sheaves 2009). Similarly, we suggest that increased proximity in coastal seascapes is able to modify niche space and increase complementarity within a number of important functional groups (Blüthgen and Klein 2011; Rosenfeld 2002). While it is important to highlight that our study was completed on only one occasion over the austral winter, we expect that these strong effects of nearshore reefs would likely occur throughout the year due to the importance of structural complexity for biological and functional diversity in ecosystems more broadly.

It is widely accepted that ecosystems with a greater number of connections between habitats can support a greater abundance and diversity of wildlife and the ecological functions they provide (Baguette et al. 2013; Nagelkerken 2009; Olds et al. 2018a). The structural changes to an ecosystem through increased proximity with complex habitats increase the number of available niches under which different species are able to feed, providing a more functionally complex ecosystem (Duffy et al. 2007; Graham and Nash 2012). We did, however, not find strong correlations between fish functional diversity and proximity to headlands, estuaries, or urban structures, habitats which have previously been shown to be of high importance to fish in surf zones (Marin Jarrin et al. 2016; Mosman et al. 2020). There is evidence from elsewhere around the world that headlands and jetties that extend out from beaches into surf zones can impede fish movement into the surf zone; however, the coastline that we work on here does not contain coastal jetties, and headlands were not always located at the mouth of an estuary, nor did they always contain extensive rocky structures that extended out into the surf zone (Marin Jarrin and Miller 2016; Marin Jarrin et al. 2016). These factors likely lead to the reduced impacts of headlands and urbanisation on fish functional diversity. Similarly, it has previously been highlighted that surf zones act as a critical link between estuaries and offshore environments (Olds et al. 2018b), which is not shown to be the case in this study. We expect that the effects of estuarine proximity on functional diversity are likely being reduced, rather than not being present, due to the functional variety of species found on reefs. Here, we find that beaches that are in close proximity to rocky reefs $(<660 \mathrm{~m})$ supported a greater overall functional diversity and different fish functional groups were found to have greater levels of functional niche size and species richness, suggesting that they have greater levels of functional complementarity. This was not found to be the case when looking at beaches near estuaries, with many estuarine fish species fitting into the zoobenthivore functional grouping, rather than resulting in functional complementarity across all functional groupings (Henderson et al. 2020; Mosman et al. 2020). Maintaining high levels of complementarity in the functional traits of animal assemblages within an ecosystem should be a key focus of management approaches and here we show that highly connected seascapes should remain a key link in the management of coastal ecosystems (Bellwood et al. 2003; Duffy et al. 2007; Rosenfeld 2002). High levels of complementarity in systems that experience patchy productivity due to allochthonous derived resources have been identified elsewhere, with investigations into the relationship between biodiversity and ecosystem functioning in different forest fragments (Paquette and Messier 2011) or beaches (Brown et al. 2015).

Habitats of greater structural complexity and habitatforming species are often considered to be more speciose and support more functional niches. However, across an entire land- or seascape mosaic of habitats, there are often many habitats that play a key role in the movement of organisms and energy throughout (Duffy et al. 2007; Graham and Nash 2012; Hyndes et al. 2014). Within coastal seascapes, surf zones have traditionally been viewed to have low structural habitat complexity and 'harsh' hydrodynamic 
conditions (McLachlan 1983); they are, however, a critical link in the movement of individuals between estuarine/ inshore and offshore ecosystems (Olds et al. 2018b). We detected 70 species in seven functional feeding groups over the austral winter, suggesting that surf zones support fish biodiversity that can match that of complex estuarine mosaics (i.e., composed of mangroves, rocks, seagrass, mudflats, sandbanks, and deep channels) (Gilby et al. 2018; Olds et al. 2012), and the levels of invertebrate biodiversity found on beaches (Marin Jarrin and Shanks 2011). Of the seventy species recorded in this study, only fourteen were found exclusively in surf zones where rocky reefs were directly under the areas of breaking waves; this suggests that many of the species we found will frequently use surf zones. While surf zones do not offer large areas of protection from predators, there are a large number of functional niches present within this ecosystem's food web (Ayvazian and Hyndes 1995; Borland et al. 2017). Most species move throughout a variety of habitats in coastal seascapes (e.g., rocky and coral reefs, pelagic environments, mangrove forests, and seagrass meadows), and we have shown here that a large number of functionally diverse species do use and reside in surf zones, highlighting the need to manage this ecosystem in a broader seascape context, where sandy beach ecosystems and their surf zones form part of the broader conservation ambit (Sheaves 2009; Stoms et al. 2005).

Seascape proximity to complex habitats shapes the functional characteristics of numerous ecosystems on land and in the sea. We provide empirical evidence that habitat proximity can structure functional diversity and complementarity in the surf zones of ocean beaches, a system traditionally viewed as having low habitat heterogeneity. Functional diversity and functional group complementarity of fish assemblages peaked at beaches with surf zones that were better connected to subtidal rocky reefs offshore, enhancing ecological resilience. Therefore, given the importance of recreational and commercial fishing in this ecosystem and the economic, social, and cultural significance of the world's sandy beaches and their surf zones, effective management and conservation of these systems will increasingly need to incorporate the principles of ecological connectivity and functional complementarity.

Supplementary Information The online version contains supplementary material available at https://doi.org/10.1007/s12237-022-01046-0.

Acknowledgements We warmly thank Tyson Jones, Brandon Hourigan, Ashley Rummell, Lucy Goodridge Gaines, Sarah Thackwray, Felicity Hardcastle, Nick Yabsley, and Olivia Kimber for their help in the field and lab.

Author Contribution $\mathrm{CJH}, \mathrm{BLG}, \mathrm{ADO}, \mathrm{RMC}$, and TAS contributed to the design of the study. CJH and JDM completed the fieldwork. CJH, BLG, ADO, JDM, and TAS contributed to the data analysis. All authors contributed to the writing and editing of the manuscript.
Funding Open Access funding enabled and organized by CAUL and its Member Institutions. Funding for this project was provided by the Sunshine Coast Council and Yaroomba Beach.

Data Accessibility Data for this project is available at the following https://doi.org/10.5281/zenodo.3333462.

Open Access This article is licensed under a Creative Commons Attribution 4.0 International License, which permits use, sharing, adaptation, distribution and reproduction in any medium or format, as long as you give appropriate credit to the original author(s) and the source, provide a link to the Creative Commons licence, and indicate if changes were made. The images or other third party material in this article are included in the article's Creative Commons licence, unless indicated otherwise in a credit line to the material. If material is not included in the article's Creative Commons licence and your intended use is not permitted by statutory regulation or exceeds the permitted use, you will need to obtain permission directly from the copyright holder. To view a copy of this licence, visit http://creativecommons.org/licenses/by/4.0/.

\section{References}

Ayvazian, S., and G. Hyndes. 1995. Surf-zone fish assemblages in south-western Australia: Do adjacent nearshore habitats and the warm Leeuwin Current influence the characteristics of the fish fauna? Marine Biology 122: 527-536.

Baguette, M., S. Blanchet, D. Legrand, V.M. Stevens, and C. Turlure. 2013. Individual dispersal, landscape connectivity and ecological networks. Biological Reviews 88: 310-326.

Bartoń, K. 2013. MuMIn: Multi-model inference. R package version 1.9. 13. In The Comprehensive R Archive Network (CRAN), Vienna, Austria.

Bellwood, D.R., A.S. Hoey, and J.H. Choat. 2003. Limited functional redundancy in high diversity systems: Resilience and ecosystem function on coral reefs. Ecology Letters 6: 281-285.

Bellwood, D.R., R.P. Streit, S.J. Brandl, and S.B. Tebbett. 2019. The meaning of the term 'function' in ecology: A coral reef perspective. Functional Ecology 33: 948-961.

Blüthgen, N., and A.-M. Klein. 2011. Functional complementarity and specialisation: The role of biodiversity in plant-pollinator interactions. Basic and Applied Ecology 12: 282-291.

Borland, H.P., T.A. Schlacher, B.L. Gilby, R.M. Connolly, N.A. Yabsley, and A.D. Olds. 2017. Habitat type and beach exposure shape fish assemblages in the surf zones of ocean beaches. Marine Ecology Progress Series 570: 203-211.

Brandl, S.J., and D.R. Bellwood. 2014. Individual-based analyses reveal limited functional overlap in a coral reef fish community. Journal of Animal Ecology 83: 661-670.

Brown, M.B., T.A. Schlacher, D.S. Schoeman, M.A. Weston, C.M. Huijbers, A.D. Olds, and R.M. Connolly. 2015. Invasive carnivores alter ecological function and enhance complementarity in scavenger assemblages on ocean beaches. Ecology 96: 2715-2725.

Cadotte, M.W., K. Carscadden, and N. Mirotchnick. 2011. Beyond species: Functional diversity and the maintenance of ecological processes and services. Journal of Applied Ecology 48: 1079-1087.

Cardinale, B.J., D.S. Srivastava, J.E. Duffy, J.P. Wright, A.L. Downing, M. Sankaran, and C. Jouseau. 2006. Effects of biodiversity on the functioning of trophic groups and ecosystems. Nature 443: 989-992.

Cheal, A.J., M. Emslie, M.A. MacNeil, I. Miller, and H. Sweatman. 2013. Spatial variation in the functional characteristics of herbivorous fish communities and the resilience of coral reefs. Ecological Applications 23: 174-188. 
Clavel, J., R. Julliard, and V. Devictor. 2011. Worldwide decline of specialist species: Toward a global functional homogenization? Frontiers in Ecology and the Environment 9: 222-228.

Duffy, J.E., B.J. Cardinale, K.E. France, P.B. McIntyre, E. Thébault, and M. Loreau. 2007. The functional role of biodiversity in ecosystems: Incorporating trophic complexity. Ecology Letters 10: 522-538.

Elliott, M., A.K. Whitfield, I.C. Potter, S.J. Blaber, D.P. Cyrus, F.G. Nordlie, and T.D. Harrison. 2007. The guild approach to categorizing estuarine fish assemblages: A global review. Fish and Fisheries 8: 241-268.

Ellis, D. 1995. Evaluation of video camera technique for indexing abundances of juvenile pink snapper Pristipomoides filamentosus, and other Hawaiian insular shelf fishes. Fishery Bulletin 93: 67-77.

Fetzer, I., K. Johst, R. Schäwe, T. Banitz, H. Harms, and A. Chatzinotas. 2015. The extent of functional redundancy changes as species' roles shift in different environments. Proceedings of the National Academy of Sciences 112: 14888-14893.

Fischer, J., and D.B. Lindenmayer. 2007. Landscape modification and habitat fragmentation: A synthesis. Global Ecology and Biogeography 16: 265-280.

Froese, R., and D. Pauly. 2018. FishBase 2000: concepts, design and datasources. In ICLARM. Los Baños, Laguna.

Gagic, V., I. Bartomeus, T. Jonsson, A. Taylor, C. Winqvist, C. Fischer, E.M. Slade, I. Steffan-Dewenter, M. Emmerson, and S.G. Potts. 2015. Functional identity and diversity of animals predict ecosystem functioning better than species-based indices. Proceedings of the Royal Society of London B: Biological Sciences 282: 20142620.

Gilby, B.L., A.D. Olds, R.M. Connolly, P.S. Maxwell, C.J. Henderson, and T.A. Schlacher. 2018. Seagrass meadows shape fish assemblages across estuarine seascapes. Marine Ecology Progress Series 588: 179-189.

Graham, N.A.J., and K.L. Nash. 2012. The importance of structural complexity in coral reef ecosystems. Coral Reefs 32: 1-12.

Harvey, E.S., M. Cappo, J.J. Butler, N. Hall, and G.A. Kendrick. 2007. Bait attraction affects the performance of remote underwater video stations in assessment of demersal fish community structure. Marine Ecology Progress Series 350: 245-254.

Henderson, C.J., B.L. Gilby, T.A. Schlacher, R.M. Connolly, M. Sheaves, P.S. Maxwell, N. Flint, H.P. Borland, T.S.H. Martin, B. Gorissen, and A.D. Olds. 2020. Landscape transformation alters functional diversity in coastal seascapes. Ecography 43: 138-148.

Henderson, C.J., T. Stevens, S.Y. Lee, B.L. Gilby, T.A. Schlacher, R.M. Connolly, J. Warnken, P.S. Maxwell, and A.D. Olds. 2019. Optimising seagrass conservation for ecological functions. Ecosystems 22: $1368-1380$.

Hill, N.A., V. Lucieer, N.S. Barrett, T.J. Anderson, and S.B. Williams. 2014. Filling the gaps: Predicting the distribution of temperate reef biota using high resolution biological and acoustic data. Estuarine, Coastal and Shelf Science 147: 137-147.

Hyndes, G.A., I. Nagelkerken, R.J. McLeod, R.M. Connolly, P.S. Lavery, and M.A. Vanderklift. 2014. Mechanisms and ecological role of carbon transfer within coastal seascapes. Biological Reviews 89: 232-254.

Laliberté, E., and P. Legendre. 2010. A distance-based framework for measuring functional diversity from multiple traits. Ecology 91 : 299-305.

Layman, C.A., D.A. Arrington, C.G. Montaña, and D.M. Post. 2007. Can stable isotope ratios provide for community-wide measures of trophic structure? Ecology 88: 42-48.

Lohbeck, M., F. Bongers, M. Martinez-Ramos, and L. Poorter. 2016. The importance of biodiversity and dominance for multiple ecosystem functions in a human-modified tropical landscape. Ecology 97: 2772-2779.
Loreau, M., and C. de Mazancourt. 2013. Biodiversity and ecosystem stability: A synthesis of underlying mechanisms. Ecology Letters 16: $106-115$.

Marin Jarrin, J.R., and J.A. Miller. 2016. Spatial variability of the surf zone fish and macroinvertebrate community within dissipative sandy beaches in Oregon, USA. Marine Ecology 37: $1027-1035$

Marin Jarrin, J.R., S.L. Miño Quezada, L.E. Dominguez-Granda, S.M. Guartatanga Argudo, and M.d.P.C.R. de Grunauer. 2016. Spatiotemporal variability of the surf-zone fauna of two Ecuadorian sandy beaches. Marine and Freshwater Research 67: 566-577.

Marin Jarrin, J.R., and A.L. Shanks. 2011. Spatio-temporal dynamics of the surf-zone faunal assemblages at a Southern Oregon sandy beach. Marine Ecology 32: 232-242.

Maslo, B., T.A. Schlacher, M.A. Weston, C.M. Huijbers, C. Anderson, B.L. Gilby, A.D. Olds, R.M. Connolly, and D.S. Schoeman. 2016. Regional drivers of clutch loss reveal important trade-offs for beachnesting birds. PeerJ 2016.

Mason, N.W., D. Mouillot, W.G. Lee, and J.B. Wilson. 2005. Functional richness, functional evenness and functional divergence: The primary components of functional diversity. Oikos 111: $112-118$.

Mayer-Pinto, M., V. Cole, E. Johnston, A. Bugnot, H. Hurst, L. Airoldi, T. Glasby, and K. Dafforn. 2018. Functional and structural responses to marine urbanisation. Environmental Research Letters 13: 014009.

McLachlan, A. 1983. Sandy beach ecology-A review. In Sandy beaches as ecosystems, 321-380: Springer.

Micheli, F., and B.S. Halpern. 2005. Low functional redundancy in coastal marine assemblages. Ecology Letters 8: 391-400.

Mosman, J.D., C.J. Henderson, A.D. Olds, B.L. Gilby, and T.A. Schlacher. 2020. Seascape connectivity exerts differing effects for fish assemblages in distinct habitats of the surf zones of ocean beaches. ICES Journal of Marine Science.

Mouchet, M.A., S. Villéger, N.W.H. Mason, and D. Mouillot. 2010. Functional diversity measures: An overview of their redundancy and their ability to discriminate community assembly rules. Functional Ecology 24: 867-876.

Mouillot, D., N.A. Graham, S. Villéger, N.W. Mason, and D.R. Bellwood. 2013. A functional approach reveals community responses to disturbances. Trends in Ecology \& Evolution 28: 167-177.

Nagelkerken, I. 2009. Ecological connectivity among tropical coastal ecosystems: Springer.

Nash, K.L., N.A.J. Graham, S. Jennings, S.K. Wilson, and D.R. Bellwood. 2016. Herbivore cross-scale redundancy supports response diversity and promotes coral reef resilience. Journal of Applied Ecology 53: 646-655

Nock, C.A., A. Paquette, M. Follett, D.J. Nowak, and C. Messier. 2013. Effects of urbanization on tree species functional diversity in eastern North America. Ecosystems 16: 1487-1497.

Olds, A.D., R.M. Connolly, K.A. Pitt, and P.S. Maxwell. 2012. Primacy of seascape connectivity effects in structuring coral reef fish assemblages. Marine Ecology Progress Series 462: 191-203.

Olds, A.D., I. Nagelkerken, C.M. Huijbers, B.L. Gilby, S.J. Pittman, and T.A. Schlacher. 2018a. Connectivity in coastal seascapes. In Seascape ecology, ed. S.J. Pittman, 261-292. Oxford, UK: John Wiley and Sons.

Olds, A.D., E. Vargas-Fonseca, R.M. Connolly, B.L. Gilby, C.M Huijbers, G.A. Hyndes, C.A. Layman, A.K. Whitfield, and T.A. Schlacher. 2018b. The ecology of fish in the surf zones of ocean beaches: A global review. Fish and Fisheries 19: 78-89.

Ortodossi, N.L., B.L. Gilby, T.A. Schlacher, R.M. Connolly, N.A. Yabsley, C.J. Henderson, and A.D. Olds. 2019. Effects of seascape connectivity on reserve performance along exposed coastlines. Conservation Biology 33: 580-589. 
Paquette, A., and C. Messier. 2011. The effect of biodiversity on tree productivity: From temperate to boreal forests. Global Ecology and Biogeography 20: 170-180.

Petchey, O.L., and K.J. Gaston. 2006. Functional diversity: Back to basics and looking forward. Ecology Letters 9: 741-758.

Quantum, G. 2013. Development Team. 2013. Quantum GIS geographic information system. Open Source Geospatial Foundation Project.

Rolo, V., P.I. Olivier, M. Pfeifer, and R.J. van Aarde. 2018. Functional diversity mediates contrasting direct and indirect effects of fragmentation on below- and above-ground carbon stocks of coastal dune forests. Forest Ecology and Management 407: 174-183.

Rosenfeld, J.S. 2002. Functional redundancy in ecology and conservation. Oikos 98: 156-162.

Rudnick, D., S. Ryan, P. Beier, S. Cushman, F. Dieffenbach, C. Epps, L. Gerber, J. Hartter, J. Jenness, and J. Kintsch. 2012. The role of landscape connectivity in planning and implementing conservation and restoration priorities. Ecological Society of America.

Schlacher, T.A., M.A. Weston, D.S. Schoeman, A.D. Olds, C.M. Huijbers, and R.M. Connolly. 2015. Golden opportunities: A horizon scan to expand sandy beach ecology. Estuarine, Coastal and Shelf Science 157: 1-6.

Sheaves, M. 2009. Consequences of ecological connectivity: The coastal ecosystem mosaic. Marine Ecology, Progress Series 391: 107-115.

Stoms, D.M., F.W. Davis, S.J. Andelman, M.H. Carr, S.D. Gaines, B.S. Halpern, R. Hoenicke, S.G. Leibowitz, A. Leydecker, and E.M. Madin. 2005. Integrated coastal reserve planning: Making the land-sea connection. Frontiers in Ecology and the Environment 3: 429-436.
Valesini, F.J., I.C. Potter, and K.R. Clarke. 2004. To what extent are the fish compositions at nearshore sites along a heterogeneous coast related to habitat type? Estuarine, Coastal and Shelf Science 60: 737-754.

Vargas-Fonseca, E., A.D. Olds, B.L. Gilby, R.M. Connolly, D.S. Schoeman, C.M. Huijbers, G.A. Hyndes, and T.A. Schlacher. 2016. Combined effects of urbanization and connectivity on iconic coastal fishes. Diversity and Distributions 22: 1328-1341.

Wainwright, P.C., and B.A. Richard. 1995. Predicting patterns of prey use from morphology of fishes. Environmental Biology of Fishes 44: 97-113.

Watson, D.L., E.S. Harvey, M.J. Anderson, and G.A. Kendrick. 2005. A comparison of temperate reef fish assemblages recorded by three underwater stereo-video techniques. Marine Biology 148: $415-425$.

Willis, T.J., and R.C. Babcock. 2000. A baited underwater video system for the determination of relative density of carnivorous reef fish. Marine and Freshwater Research 51: 755-763.

Wood, S., and M.S. Wood. 2015. Package 'mgcv.' R Package Version 1: 29 .

Wraith, J., T. Lynch, T.E. Minchinton, A. Broad, and A.R. Davis. 2013. Bait type affects fish assemblages and feeding guilds observed at baited remote underwater video stations. Marine Ecology Progress Series 477: 189-199. 